\title{
Belo Monte: desenvolvimento para quem?
}

Denise Maria Maia*

RESUMO - O texto parte da polêmica sobre a necessidade ou não da construção da usina de Belo Monte bem como sobre a forma pela qual esse processo tem sido conduzido. $\mathrm{Na}$ abordagem, destaca-se a pouca centralidade que o ser humano ocupa na discussão em defesa da proposta. Demonstra-se a contundência dos questionamentos de construções de mega hidrelétricas na região amazônica e como, consequentemente, comprometem o desenvolvimento sustentável.

Palavras-chave: Energia. Hidrelétricas. Meio ambiente. Desenvolvimento humano sustentável.

\section{INTRODUÇÃO}

Da polêmica gerada pela construção da usina hidrelétrica Belo Monte, pouca atenção se volta a um aspecto bastante vulnerável do seu projeto: as pessoas! A distância que existe entre o principal argumento que funda a proposta da sua existência, de suprir necessidade de energia para a população que cresce, com a insegurança hídrica imposta à população local para manter seus modos de vida, não parece incoerente para os que defendem sua construção nem para a grande mídia. Se por um lado na proposta supostamente se atenderiam as necessidades de consumo futuro de pessoas, por outro praticamente se ignora o impacto sobre a vida daquelas que são moradoras na região. Essa vulnerabilidade está presente na precária avaliação apresentada e nas formas propostas para contorná-las ou minimizá-las. O pressentimento de um resultado desastroso para ribeirinhos e comunidades indígenas transformados em refugiados ambientais faz brotar questões anteriores a toda essa polêmica, como: de qual desenvolvimento falamos? A quem serve esse desenvolvimento? Por certo outras questões também causam mal-estar, como por que insistimos em manter nossos já velhos estilos de vida e de consumo, tão e cada vez mais questionados.

No momento em que se repensa profundamente nosso modo de viver, com desastres ambientais em sequência capazes de fazer muitos dos mais céticos mudarem seu anterior descaso com a natureza, em plena década da biodiversidade, especialmente no ano 2011 proclamado como Ano Internacional das Florestas pelas Nações Unidas, no ano em que a Igreja se posiciona claramente em defesa da vida ao lançar a Campanha da Fraternidade com o tema

\footnotetext{
* Doutora em educação pela Universidade Federal de Minas Gerais. É professora do Departamento de Economia da Universidade Federal do Paraná. Endereço eletrônico: denimaia@ufpr.br.
} 
do meio ambiente ${ }^{1}$, o governo, por cima de todos os argumentos e dos apelos da procuradoria da justiça e de movimentos sociais, passa ao largo para manter Belo Monte a qualquer custo e a qualquer preço.

O bispo auxiliar do Rio de Janeiro e secretário-geral da CNBB, Dimas Lara Barbosa, a respeito das hidrelétricas previstas para a Amazônia, afirma que a "necessidade de energia não pode justificar projetos que ignoram o meio ambiente, desalojam povos inteiros, matam culturas.". Ele alerta no texto base da campanha: "A Amazônia, tão valiosa para o país e para a humanidade, parece ser vista como um vazio demográfico e improdutivo que, ao menos, deve produzir energia, mesmo a despeito do alto custo para a sua diversidade." (BARBOSA, 2011, p. A3), e bem lembra que sustentabilidade passa necessariamente por mudança de hábitos nos padrões de consumo, especialmente dos que gastam em demasia.

Tratada como terra de ninguém, na floresta amazônica grassam fraudes e exploração. O delicado e frágil sistema sofre a dificuldade e os obstáculos do arcabouço regulamentar e fiscalizador. Para ilustrar a atualidade da crítica, tomemos, por exemplo, o Programa Terra Legal²: Sua ação alcançou a vergonhosa cifra de 1,1\% da meta de 2010, estipulada em 50 mil títulos fundiários.

O manejo sustentável de florestas é discutido hoje como forma de conter sua alarmante degradação: dos remanescentes $20 \%$ da cobertura florestal original ainda existentes no planeta, 13 milhões de hectares/ano foram convertidos para outros usos. Esse patrimônio natural é essencial para a manutenção de toda a vida no planeta, sustentar a economia global e combater mudanças climáticas (NUNES, 2011).

Com o objetivo de sensibilizar a sociedade para a importância da floresta em favor da vida sustentável no mundo, no decorrer do ano os eventos programados para marcar o Ano das Florestas ressaltarão o valor destas também para a economia e para a erradicação da pobreza: fornecedoras de produtos madeireiros e não madeireiros, fontes de plantas medicinais conhecidas e de objeto de pesquisas e estudos, produtora de água potável, redutora da poluição do ar, protetora da biodiversidade, supridora das necessidades básicas e de subsistência e até promotora de serviços de recreação e turismo. O uso sustentável da floresta promove a manutenção e fertilização do solo, ajuda populações rurais a suprir sua existência e cumpre prioritariamente a função social de inclusão de populações indígenas e comunidades tradicionais. O conjunto 1 O lançamento da Campanha da Fraternidade deste ano, lançada pela Conferência Nacional dos Bispos no Brasil na quarta-feira de cinzas, elege a vida no planeta como tema, e posiciona também a Igreja, frente a ameaças nunca antes imagináveis, a favor do desenvolvimento respeitoso com a natureza e com a inclusão de todos. (BARBOSA, 2011).

2 Programa de regularização fundiária de áreas da Amazônia pertencentes à União, ocupadas por particulares. Referem-se a 510 mil quilômetros quadrados com documentação duvidosa ou ausente. 
das florestas brasileiras representa o segundo maior, em extensão, no mundo, e o maior em florestas tropicais, com aproximadamente $26 \%$ do total das remanescentes. Temos alguns dos biomas mais ricos do mundo e esta "megadiversidade terrestre está intrinsecamente relacionada à conservação da cobertura florestal nacional.” (CORRÊA, 2011).

\section{A POLÊMICA E O CONTEXTO}

Hoje não precisamos criar mais empregos que degradem a natureza e a floresta, especialmente da região amazônica, pela sua complexidade, pela dificuldade de levantamentos de informações, de controle e proteção de abusos ${ }^{3}$. Não precisamos reproduzir esse formato de relações subordinadas com um mundo em ebulição, já farto de tanta desigualdade. Ou preferimos cultivar para a nação esse vergonhoso lugar de campeã da concentração de riqueza?

A usina hidrelétrica de Belo Monte, aprovada no leilão realizado em 20 de abril de 2010 para ser construída na Volta Grande do rio Xingu (PA), terá potência máxima instalada de 11 mil megawatts, mas média de apenas 4,5 mil megawatts, capaz de atender, segundo estimativas, a 22 milhões de residências/ano. A previsão é de gerar 23 mil empregos diretos e aproximadamente 100 mil indiretos, o que desencadeará um processo de especulação imobiliária e de desmatamento não controlável pela empresa vencedora, a Norte Energia, criada e ampliada a partir de um consórcio, hoje com 18 empresas públicas, privadas e ONG’s.

Nos mapas apresentados a seguir pode-se observar a localização da usina na floresta amazônica e seu entorno.

FIGURA 1 - LOCALIZAÇÃO DA USINA DE BELO MONTE

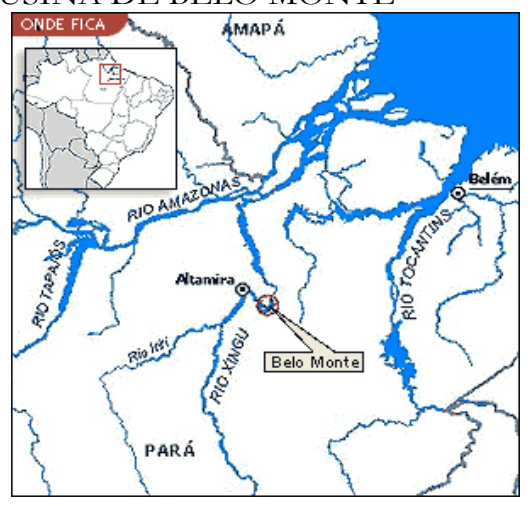

FONTE: Rede da Sustentabilidade.

3 As denúncias pipocam em várias frentes, e atingem o próprio executivo: em notícia do jornal Folha de São Paulo de 06/03/2011, p. A9, Sidney Rosa, nomeado Secretário Estadual de Projetos Estratégicos, acusado de manter trabalhadores rurais em situações análogas à escravidão, diz não existir definição do que é trabalho escravo, brecha para fiscalização classificar pequenas irregularidades dessa forma. Mais recentemente, acompanhamos na mídia a greve dos operários da Usina de Santo Antônio, no rio Madeira, Rondônia, e a revolta dos operários na Usina Hidrelétrica de Jirau, cujas empresas responsáveis são acusadas de violação dos direitos humanos. 
FIGURA 2 - COMO SERÁ O AHE BELO MONTE

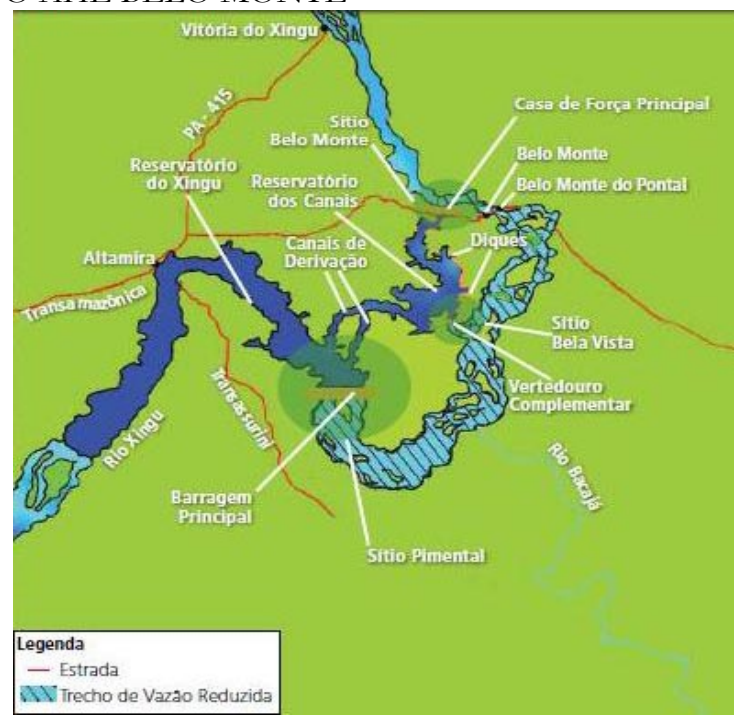

FONTE: Notícias da Amazônia.

A construção afetará os povos do Xingu, de Altamira, dos ribeirinhos e indígenas que habitam em vários grupos às margens do rio no estado do Pará. Os protestos vêm desde o Parque Indígena do Xingu, onde dezesseis etnias se empenham em manter tradições e costumes: representantes do povo Kisêdjê, também conhecido como Suya, da terra Indígena Wawi, garantem que a comunidade xinguana se unirá contra a construção da barragem por temer os impactos que causarão.

Nosso potencial energético hídrico não poderia ser mais bem aproveitado? Seriam quinhentos quilômetros quadrados inundados, aproximadamente 25 bilhões investidos, além de incentivos fiscais e creditícios: financiamento do BNDES de até 13 bilhões (mais juros), com prazo de até 30 anos e desconto de 75\% do imposto de renda, por 10 anos, aos moldes, de fato, de uma tarifa subsidiada pelo contribuinte. Esse modelo, após renúncia de seu dirigente, é sustentado e referendado pela instituição encarregada supostamente de proteger nossa riqueza natural e os cidadãos dos riscos - o IBAMA. Os esforços do setor público em enfrentar as controvérsias são enormes, com empresários, técnicos, e ambientalistas, mas não suficientes para garantir a sustentabilidade ambiental do projeto, transparente na crise do IBAMA, cujo presidente interino há de tomar decisões a respeito.

Vamos repetir a história, não bastasse a tragédia que foi para a população indígena a descoberta da América? As vítimas são as mesmas. Indicadores de como exterminamos a população indígena, jovens negros e pobres não faltam, embora ainda insuficientes para sensibilizar e apontar para uma responsabilidade consciente dos nossos papéis. Problemas ambientais alcançam os noticiários! Aquecimento global, desmatamentos, erosão dos solos, extermínio da vida 
marítima, esgotamento de recursos energéticos... Mas não a construção de Belo Monte!

A guerra de liminares entre o Ministério Público Federal e a Advocacia Geral da União, mais os protestos de ambientalistas e organizações sociais são anteriores. Há 25 ou 30 anos ela está em discussão, mas nem por isso foram produzidas respostas suficientes e convincentes às inúmeras questões postas e repostas.

Recentemente a nona vara da Justiça Federal do Pará suspendeu licença ambiental parcial para instalação do canteiro de obras da usina no rio Xingu e impediu também a transferência de recursos financeiros à Norte Energia. A Advocacia Geral da União (AGU) derrubou em 3 de março de 2011, no Tribunal Regional Federal (TRP), a decisão que suspendia a instalação do canteiro de obras da usina hidrelétrica de Belo Monte (PA). Ao permitir a simples instalação do canteiro de obras, a AGU já mobilizou cerca de oito mil pessoas para a região, sem tradição no uso da floresta. O recurso da Procuradoria argumenta que não está prevista em lei a licença parcial ou fracionada para a obra.

E o embate continua. O movimento Viva Xingu e mais 40 entidades encaminharam à Comissão Interamericana de Direitos Humanos (CIDH) da Organização dos Estados Americanos (OEA) pedido de medida cautelar para suspender o processo de licenciamento ambiental referente a Belo Monte. Em documento enviado pela OEA ao governo brasileiro, pedem-se informações em prazo de dez dias sobre a ação civil pública interposta pelo Ministério Público Federal a respeito da licença parcial à Empresa Norte Energia (PEDUZZI, 2011).

A defesa da usina, quando respeitável, é constrangedora. O ex-presidente da Eletrobras, Luiz Pinguelli Rosa (ROSA, 2011) reconhece como justas as preocupações ambientais e não defende com convicção a usina. Ele também revela preocupações e posiciona-se solidária e criticamente nas questões sociais e ambientais levantadas pelos opositores. O debate fez contraponto com Marcelo Furtado (FURTADO, 2011), diretor executivo do Greenpeace no Brasil, para quem o país precisa sim de energia, mas não de Belo Monte. Para Furtado, "se, do ponto de vista socioambiental, a construção de Belo Monte tem tudo para ser um desastre, do ponto de vista econômico, ela também não faz sentido.”. Ambos reconhecem que a discussão está em torno do tamanho da obra e sua localização, ou seja, adotar ou não hidrelétricas de potência significativa em plena floresta amazônica.

O relatório do Greenpeace adverte para o alto risco de improvisações, cujos efeitos duram por décadas. As vantagens comparativas do Brasil são reconhecidas e devem ser bem aproveitadas segundo o referido relatório, com “o aproveitamento das grandes potencialidades de nossas fontes eólicas, solares e de pequenas hidrelétricas.”(MARTINS, 2011). 


\section{PROPOSTAS}

$\mathrm{Na}$ nossa história foram naturalizadas ações de uma sociedade violenta desde sua ocupação. Mas não podemos olhar para o futuro sem sermos respeitosos no presente, se pretendemos ser uma nação justa e sem pobreza. Faltou-nos no passado e nos falta no presente colocar o ser humano como valor central, reconhecê-lo não isolado, mas em dinâmica com outros seres dentro de âmbitos condicionantes, reconhecer o vínculo da matriz social com a ambiental.

Cada vez mais não basta avançar, é preciso saber para onde! O que estamos produzindo, para quem, como estamos produzindo, com que impactos sociais? Avanços tecnológicos para quem? Ainda há muito que democratizar, mas ainda é mais urgente saber como e para quem servirá o desenvolvimento tecnológico, mais do que privilegiar interesses humanitários. Compor um ambiente de confiança para prevalecer o bom senso e interesse da verdadeira sustentabilidade. Os critérios não são neutros, dizem respeito aos cidadãos e, portanto se impõe a necessidade de ampliar o debate para além dos especialistas. Sua legitimidade deve ser construída necessariamente com transparência, pari passu ao entendimento dos anseios da sociedade, para que, ao eleger entre as opções reais, nenhuma seja ilusória.

\section{REFERÊNCIAS}

BANCOS e empresas associadas a Belo Monte podem ter reputação colocada em xeque. Disponível em: <http://www.sustentabilidade.org.br/info_det.asp?codigo=1272>.

BARBOSA, D. L. Em defesa da vida no planeta terra. Folha de São Paulo, São Paulo, mar. 2011.

CORRÊA, C. Ministra abre ano internacional das florestas no brasil. Jornal Dia Dia. Disponível em: <http://www.jornaldiadia.com.br/jdd/temperatura-e-meio-ambiente/53516--ministra-abre-ano-internacional-das-florestas-no-brasil $>$.

FURTADO, M. O futuro da energia no retrovisor. Folha de São Paulo, São Paulo, fev. 2011. NUNES, M. Na década da biodiversidade, o ano internacional das florestas. Carta Capital, mar. 2011. Disponivel em: < http://www.cartamaior.com.br/templates/materiaMostrar. cfm?materia_id $=17575>$. Acesso em: 23/3/2011.

MARTINS, A. De que revolução se trata. Biblioteca Diplô, abr. 2007. Disponivel em: < http:/ / diplo.org.br/imprima1556>. Acesso em: 3/3/2011.

MINISTRO diz que Belo Monte é a usina mais planejada do mundo e que obras começam em setembro. Disponível em: <http://www.noticiasdaamazonia.com.br/12009-ministro-dizque-belo-monte-e-a-usina-mais-planejada-do-mundo-e-que-obras-comecam-em-setembro/>. Acesso em: 17/3/2011.

PEDUZZI, P. Belo Monte: OEA quer informações. Portal Ambiente e Energia-Agência Brasil. Disponivel em: <http://www.ambienteenergia.com.br/index.php/2011/03/belomonte-oea-quer-informacoes/9931>.

ROSA, L. P. A razão das hidrelétricas. Folha de São Paulo, São Paulo, fev. 2011. 